\title{
Changing Characteristics of Extravascular Lung Water After Fluid Resuscitation in Septic Shock Patients by Early PiCCO Monitoring
}

\author{
Chanjuan Ji ${ }^{*}$, Jinliang Hu, Qing Ye \\ Department of Operating, Binzhou People's Hospital, Binzhou City, China
}

Email address:

ChanjuanJi2019@163.com (Chanjuan Ji)

${ }^{*}$ Corresponding author

\section{To cite this article:}

Chanjuan Ji, Jinliang Hu, Qing Ye. Changing Characteristics of Extravascular Lung Water After Fluid Resuscitation in Septic Shock Patients by Early PiCCO Monitoring. Science Journal of Public Health. Vol. 7, No. 6, 2019, pp. 187-192. doi: 10.11648/j.sjph.20190706.12

Received: August 31, 2019; Accepted: October 26, 2019; Published: November 8, 2019

\begin{abstract}
This study aims to explore the changing characteristics of extravascular lung water after fluid resuscitation in septic shock patients by early PiCCO monitoring. 42 patients who were admitted to the ICU in our hospital and diagnosed as septic shock were collected. The patients were divided into two groups: treatment group (PiCCO group) ( $\mathrm{n}=21)$ and control group (CVP group) $(\mathrm{n}=21)$. They were given early fluid resuscitation using different monitoring methods on the basis of conventional treatment for septic shock to monitor the changes of hemodynamics, EVLWI, oxygenation index $\left(\mathrm{PaO}_{2} / \mathrm{FiO}_{2}\right)$ and $\mathrm{BNP}$ level before and after resuscitation. The BNP and LAC levels of the treatment group were significantly lower than those of the control group within $72 \mathrm{~h}(\mathrm{P}<0.05)$. The use time of vasoactive drug, duration of mechanical ventilation and length of stay in ICU were significantly shorter in the treatment group than those in the control group $(\mathrm{P}<0.05)$, but there were no significant differences in the incidence of MODS and mortality between the two groups $(\mathrm{P}>0.05)$. ITBVI and GEDVI immediately, $12 \mathrm{~h}$ and $24 \mathrm{~h}$ after the fluid resuscitation were increased in the two groups compared with those before, between which the difference was statistically significant $(\mathrm{P}<0.01)$. Compared with those before resuscitation, the differences in $\mathrm{PaO}_{2} / \mathrm{FiO}_{2}$ at each time point in the two groups were not statistically significant $(\mathrm{P}>0.05)$. Early fluid resuscitation under the guidance of PiCCO has significant effect, which can be used as one of indicators for hemodynamic monitoring.
\end{abstract}

Keywords: PiCCO, Septic Shock, Fluid Resuscitation, Pneumonedema

\section{Introduction}

Septic shock and its secondary multiple organ dysfunction syndrome (MODS) mainly lead to death in ICU wards, which bottleneck the development of critical care medical science at present. During septic shock, hemodynamic changes are mainly featured in abnormal distribution of blood flow, resulting in significant insufficiency of effective circulating blood volume. Therefore, organ tissue is in a hypoperfusion state, leading to tissue hypoxia, metabolic dysfunction and progression. How to provide patients with sufficient capacity to ensure adequate volume resuscitation while preventing pulmonary edema from aggravating is the difficulty of the hemodynamic management in critical care medicine $[1,2]$. Therefore, for patients with septic shock, early fluid resuscitation is one of the important measures for circulatory support, and especially early goal directed therapy (EGDT) can maintain stable circulation, and improve organ tissue perfusion and tissue oxygen supply. However, clinically many patients with septic shock suffer from varying degrees of pulmonary edema and tissue edema due to increased capillary permeability. If fluid resuscitation is performed, there will be the risks of aggravated oxygen metabolism that deteriorates respiratory functions $[3,4]$.

For a long time, clinically central venous pressure (CVP) is mostly used in the hemodynamic monitoring of patients with septic shock. In recent years, a large number of studies have shown that the correlation between CVP and cardiac preload is not accurate enough for the impact of many factors. Continuous cardiac output monitoring ( $\mathrm{PiCCO})$ is a new minimally invasive hemodynamic monitoring technology, which can simultaneously monitor cardiac 
output $(\mathrm{CO})$, cardiac index $(\mathrm{CI})$ and capacity indicators such as intra-thoracic blood volume index (ITBVI), global end-dilution volume index (GEDVI), extra-vascular lung water index (EVLWI) and pulmonary vascular permeability index (PVPI), and can also monitor vascular resistance changes. In addition, PiCCO, which can be operated in a convenient and simple way, can guide the clinical treatment of critically ill patients timely and effectively $[5,6]$.

This study aims to compare the effects of early fluid resuscitation under the guidance of $\mathrm{PiCCO}$ capacity monitoring and CVP monitoring on the levels of blood-brain natriuretic peptide (BNP), lactic acid (LAC), time of vasoactive drug application and prognosis.

\section{Materials and Methods}

The experiments were approved by the Clinical Ethics Committees of the First Teaching Hospital of Xinjiang Medical University.

\subsection{General Information}

42 hospitalized patients in ICU who were diagnosed as septic shock in our hospital from January 2019 to October 2019 were collected. The patients were divided into two groups: treatment group (PiCCO group) $(\mathrm{n}=21)$, in which there were 12 males and 9 females with the mean age of (44.6 \pm 8.7 ) years old; control group (CVP group) $(n=21)$, in which there were 11 males and 10 females with the age of $(45.8 \pm 9.2)$ years old on average.

Diagnostic criteria for septic shock: 1) clinically definite infection; 2) existence of SIRS; 3) systolic blood pressure less than $90 \mathrm{mmHg}$ or more than $40 \mathrm{mmHg}$ lower than the original baseline value for at least $1 \mathrm{~h}$ or blood pressure maintained by infusion or drugs; 4) poor adverse tissue perfusion such as oliguria $(<30 \mathrm{ml} / \mathrm{h})$ for over $1 \mathrm{~h}$ or acute consciousness disorder. The shock time of onset of patients enrolled was less than $24 \mathrm{~h}$, and all patients were given mechanical ventilation auxiliary support [7].

Exclusion criteria: 1) patients above 70 years old (elderly patients had poor functional reserve of basis organs with uncertain therapeutic effect); 2) patients with large area of myocardial infarction, acute coronary syndrome and history of cardiac insufficiency; 3) patients with acute severe craniocerebral injury (severe cerebral trauma, massive cerebral hemorrhage, massive cerebral infarction and severe brain-stem injury), GCS score $<5$; 4) patients with severe underlying diseases beyond cure: active massive hemorrhage than cannot be stopped; severe abdominal infection beyond effectively drainage; advanced cancer; in dying state difficult to be cured [8].

\subsection{General Treatment}

Broad-spectrum antibiotics that could cover possible pathogens as much as possible were given to protect organ functions, monitor clotting function, kidney function, liver function, blood lactate (LAC) level, blood gas analysis changes and altered mental status, and vasoactive drugs were discontinued after the blood pressure was restored to normal after active treatment.

\subsection{Early Fluid Resuscitation}

The two groups of patients were performed early fluid resuscitation by different monitoring methods on the basis of the conventional treatment of septic shock.

\subsection{Monitor Indices}

The changes in hemodynamics, and levels of EVLWI, oxygenation index $\left(\mathrm{PaO}_{2} / \mathrm{FiO}_{2}\right)$ and $\mathrm{BNP}$ before and after fluid resuscitation were monitored.

\subsection{Fluid Supplement of the Treatment Group Under PiCCO Monitoring}

PiCCO thermosensitive catheter and central venous catheter were connected with PiCCO monitoring module respectively after being connected with the temperature probe to record the monitoring data of patients, including CI, ITBI, GEDI, EVLWI and SVV. The data reached the following levels within $12 \mathrm{~h}: 1)$ GEDI $>700 \mathrm{ml} / \mathrm{m}^{2}$ or ITBI $>850 \mathrm{ml} / \mathrm{m}^{2} ; 2$ ) mean arterial pressure $\geq 70 \mathrm{mmHg}$, urine output $\geq 0.2 \mathrm{ml} / \mathrm{kg} / \mathrm{h}$; 3 ) central venous oxygen saturation $\geq 75 \%$. Method of fluid resuscitation: the patients with $\mathrm{CI}<3.0 \mathrm{~L} / \mathrm{min} / \mathrm{m}^{2}$, if EVLWI $<10 \mathrm{ml} / \mathrm{kg}$, vasoactive drug was added to adjust CI to higher than $3.0 \mathrm{~L} / \mathrm{min} / \mathrm{m}^{2}$ and maintain EVLWI $<10 \mathrm{ml} / \mathrm{kg}$ and $\mathrm{SVV}<10 \%$. When $\mathrm{CI}>3.0 \mathrm{~L} / \mathrm{min} / \mathrm{m}^{2}$ and EVLWI $>10 \mathrm{ml} / \mathrm{kg}$, the amount of fluid was limited and diuresis was performed appropriately.

\subsection{Fluid Supplement of the Control Group by CVP Measurements}

The data reached within $12 \mathrm{~h}$ : CVP 9-11 mmHg; mean arterial pressure $\geq 70 \mathrm{mmHg}$; urine output $\geq 0.5 \mathrm{ml} / \mathrm{kg} / \mathrm{h}$; central venous oxygen saturation $\geq 75 \%$. Method of fluid resuscitation: if $\mathrm{CVP} \leq 8 \mathrm{mmHg}$, fluid infusion was applied, and if $C V P \geq 12 \mathrm{mmHg}$, the amount of fluid was limited.

\subsection{Hemodynamic Indices}

Single indicator thermodilution was used: central venous catheter was catheterized into the right internal jugular vein for continuous monitoring of CVP, and then connected with the temperature probe and PiCCO monitor (PULSION Medical Systems AG, Germany). Femoral artery was placed into PiCCO catheter (PULSION Medical Systems AG, Germany). PiCCO monitor was opened to connect with pressure transducer for continuous monitoring of invasive arterial pressure after zero setting. $30 \mathrm{~mL}$ of normal saline at $4^{\circ} \mathrm{C} \sim 10^{\circ} \mathrm{C}$ was injected via central venous catheter to measure EVLWI, ITBVI, GEDVI, CI and SI, and pulmonary capillary permeability index (PVPI) was tested using the method of single indicator thermodilution. 


\subsection{Blood Gas Analysis}

Arterial blood $\mathrm{pH}$ value, arterial partial pressure of oxygen $\left(\mathrm{PaO}_{2}\right)$, arterial partial pressure of carbon dioxide $\left(\mathrm{PaCO}_{2}\right)$ and arterial oxygen saturation $\left(\mathrm{SaO}_{2}\right)$ were measured, and the $\mathrm{PaO}_{2} / \mathrm{FiO}_{2}$ ratio was calculated.

\subsection{Statistical Analysis}

All the data were analyzed by SPSS 13.0. The measurement data were expressed as $(\mathrm{x} \pm \mathrm{s})$. The groups were compared by the $t$ test. The numeration data were subjected to the $X^{2}$ test.
$\mathrm{P}<0.05$ was considered statistically significant.

\section{Results}

\subsection{General Information}

There were no statistically significant differences in the gender, age, admission APACHE II score and basic infection focus distribution between the two groups $(\mathrm{P}>0.05)$ (Table 1).

Table 1. General information.

\begin{tabular}{lllllll}
\hline \multirow{2}{*}{ Group } & \multirow{2}{*}{ Gender (M/F) } & \multirow{2}{*}{ Age } & \multirow{2}{*}{ APACHE II } & \multirow{2}{*}{ LAC (mmol/L) } & \multicolumn{2}{c}{ Infection resource (n) } \\
\cline { 5 - 7 } & & & & Lung & Abdominal cavity & Others \\
\hline Treatment & $12 \pm 9$ & $44.6 \pm 8.7$ & $21.5 \pm 4.7$ & $6.3 \pm 2.9$ & 16 & 4 \\
Control & $11 \pm 10$ & $45.8 \pm 9.2$ & $20.6 \pm 5.3$ & $6.23 \pm 3.1$ & 15 & 5 \\
\hline
\end{tabular}

\subsection{BNP and LAC Levels Within $72 \mathrm{~h}$}

The BNP level in the treatment group showed an overall downward trend within $72 \mathrm{~h}$ of early resuscitation. Except the first $12 \mathrm{~h}$, the BNP levels at each time point in the treatment group were significantly lower than those in the control group $(\mathrm{P}<0.05)$ (Table 2).

Table 2. BNP levels within $72 \mathrm{~h}$

\begin{tabular}{lllll}
\hline Group & $\mathbf{1 2} \mathbf{h}$ & $\mathbf{2 4} \mathbf{h}$ & $\mathbf{4 8} \mathbf{h}$ & $\mathbf{7 2} \mathbf{h}$ \\
\hline Treatment & $629.4 \pm 83.6$ & $673.8 \pm 96.8^{*}$ & $485.1 \pm 83.8^{*}$ & $317.3 \pm 69.2^{*}$ \\
Control & $536.5 \pm 74.5$ & $836.7 \pm 104.5$ & $738.6 \pm 93.5$ & $638.7 \pm 83.5$ \\
\hline
\end{tabular}

$* \mathrm{P}<0.05$ vs the control group.

Compared with the control group, the blood LAC level of the treatment group gradually decreased. The LAC level of the treatment group was significantly lower than that of the control group $(\mathrm{P}<0.05)$, and the differences within $24 \mathrm{~h}$ and $48 \mathrm{~h}$ were highly significant (Table 3 ).

Table 3. LAC levels within $72 \mathrm{~h}$.

\begin{tabular}{lllll}
\hline Group & $\mathbf{1 2} \mathbf{h}$ & $\mathbf{2 4} \mathbf{h}$ & $\mathbf{4 8} \mathbf{~ h}$ & $\mathbf{7 2} \mathbf{~}$ \\
\hline Treatment & $7.2 \pm 3.5$ & $5.1 \pm 2.7^{*}$ & $2.8 \pm 1.2^{*}$ & $2.2 \pm 1.3$ \\
Control & $7.8 \pm 3.6$ & $9.8 \pm 3.4$ & $5.7 \pm 3.1$ & $3.1 \pm 1.4$ \\
\hline
\end{tabular}

$* \mathrm{P}<0.05$ vs the control group.

\subsection{Indices Before Resuscitation}

Before resuscitation, the CI and SVI levels of the control group were higher than those of the treatment group, between which the differences were statistically significant $(\mathrm{P}<0.05)$, but no significant difference was found in other indices $(\mathrm{P}>0.05)$ (Table 4).

Table 4. Hemodynamic indices before resuscitation.

\begin{tabular}{llllll}
\hline Group & $\begin{array}{l}\text { ITBVI } \\
\left(\mathbf{m l} / \mathbf{m}^{\mathbf{2}}\right)\end{array}$ & $\begin{array}{l}\text { CEDVI } \\
\left(\mathbf{m l} / \mathbf{m}^{\mathbf{2}}\right)\end{array}$ & $\begin{array}{l}\mathbf{C I} \\
\left(\mathbf{L} / \mathbf{m i n} \cdot \mathbf{m}^{\mathbf{2}}\right)\end{array}$ & $\begin{array}{l}\text { SVI } \\
\left(\mathbf{m l} / \mathbf{m}^{\mathbf{2}}\right)\end{array}$ & $\begin{array}{l}\mathbf{C V P} \\
(\mathbf{m m H g})\end{array}$ \\
\hline Treatment & $686.7 \pm 99.8$ & $538.9 \pm 75.9$ & $2.5 \pm 1.5^{*}$ & $24.7 \pm 8.9^{*}$ & $11.7 \pm 3.6$ \\
Control & $679.3 \pm 96.3$ & $536.8 \pm 73.8$ & $4.1 \pm 1.4$ & $36.8 \pm 9.5$ & $18.8 \pm 3.4$ \\
\hline
\end{tabular}

$* \mathrm{P}<0.05$ vs the control group.

\subsection{Hemodynamic Data Before and After Fluid Resuscitation}

Shock symptoms and signs changed evidently after fluid resuscitation. The results show that ITBVI and GEDVI immediately, $12 \mathrm{~h}$ and $24 \mathrm{~h}$ after fluid resuscitation were increased in the two groups compared with those before, between which the differences were statistically significant $(\mathrm{P}<0.01)$. Compared with that before resuscitation, the differences of $\mathrm{PaO}_{2} / \mathrm{FiO}_{2}$ at each time point in the two groups were not statistically significant $(\mathrm{P}>0.05)$. The $\mathrm{CI}$ and SVI levels at each time point in the control group did not significantly differ from those before resuscitation $(\mathrm{P}>0.05)$.
Nevertheless, the CI levels immediately and $2 \mathrm{~h}$ after fluid resuscitation were higher than those before resuscitation $(\mathrm{P}<0.01)$, and the SVI levels $12 \mathrm{~h}$ and $24 \mathrm{~h}$ after fluid resuscitation were increased compared with that before resuscitation $(\mathrm{P}<0.01)$. Compared with that before resuscitation, CVP in the control group was increased only in $24 \mathrm{~h}(\mathrm{P}<0.01)$, while those in the treatment group $12 \mathrm{~h}$ and 24 $\mathrm{h}$ after resuscitation were elevated $(\mathrm{P}<0.01)$. Compared with that before resuscitation, EVLWI of the two groups instantly, $12 \mathrm{~h}$ and $24 \mathrm{~h}$ after resuscitation were increased $(\mathrm{P}<0.05)$ (Table 5). 
Table 5. Hemodynamic data before and after fluid resuscitation.

\begin{tabular}{llllll}
\hline \multirow{2}{*}{ Group } & \multirow{2}{*}{ Index } & Before & After & \\
\cline { 4 - 6 } & & $716.8 \pm 116.7$ & $796.8 \pm 104.6^{*}$ & $937.5 \pm 137.6^{*}$ & $\mathbf{2 4} \mathbf{h}$ \\
\hline Treatment & \multirow{2}{*}{ ITBVI $\left(\mathrm{ml} / \mathrm{m}^{2}\right)$} & $714.9 \pm 109.4$ & $884.9 \pm 126.4^{*}$ & $901.6 \pm 108.9^{*}$ & $881.5 \pm 121.8^{*}$ \\
Treatment & & $594.6 \pm 73.8$ & $701.5 \pm 84.5^{*}$ & $731.5 \pm 115.5^{*}$ & $653.5 \pm 112.5^{*}$ \\
Control & $\mathrm{GEDVI}\left(\mathrm{ml} / \mathrm{m}^{2}\right)$ & $596.4 \pm 74.5$ & $676.8 \pm 85.5^{*}$ & $716.1 \pm 105.6^{*}$ & $694.5 \pm 106.5^{*}$ \\
Treatment & & $2.9 \pm 1.1$ & $3.7 \pm 1.3^{*}$ & $3.8 \pm 1.2^{*}$ & $3.2 \pm 1.1$ \\
Control & $\mathrm{CI}\left[\mathrm{L} /\left(\mathrm{min} \cdot \mathrm{m}^{2}\right)\right]$ & $3.8 \pm 1.1$ & $3.9 \pm 1.2$ & $3.5 \pm 1.1$ & $3.6 \pm 1.1$ \\
Treatment & & $26.1 \pm 8.7$ & $27.9 \pm 8.9$ & $31.5 \pm 10.5^{*}$ & $31.7 \pm 9.7^{*}$ \\
Control & $\mathrm{SVI}\left(\mathrm{ml} / \mathrm{m}^{2}\right)$ & $36.6 \pm 9.4$ & $38.4 \pm 10.6$ & $37.5 \pm 11.6$ & $38.9 \pm 11.9$ \\
Treatment & & $9.6 \pm 3.1$ & $9.8 \pm 3.4$ & $12.4 \pm 3.8^{*}$ & $12.9 \pm 4.1^{*}$ \\
Control & $\mathrm{CVP}(\mathrm{mmHg})$ & $11.1 \pm 2.8$ & $11.6 \pm 2.4$ & $11.4 \pm 2.6$ & $14.2 \pm 3.8^{*}$ \\
Treatment & & $192.6 \pm 34.5$ & $179.3 \pm 36.1$ & $191.3 \pm 39.1$ & $197.3 \pm 41.0$ \\
Control & $\mathrm{PaO} / \mathrm{FiO}(\mathrm{mmHg})$ & $218.6 \pm 43.6$ & $224.6 \pm 46.5$ & $227.6 \pm 50.4$ & $221.7 \pm 48.4$ \\
Treatment & & $11.5 \pm 3.0$ & $13.5 \pm 3.4^{*}$ & $15.6 \pm 4.3^{*}$ & $12.9 \pm 4.1 \#$ \\
Control & $\mathrm{EVLWI}(\mathrm{ml} / \mathrm{kg})$ & $6.7 \pm 1.2$ & $8.4 \pm 1.8 \#$ & $8.6 \pm 1.6 \#$ & $10.6 \pm 2.4^{*}$ \\
Treatment & & $48.1 \pm 12.6$ & $49.2 \pm 11.6$ & $52.4 \pm 12.7$ & $58.1 \pm 13.8 \#$ \\
Control & $\mathrm{MAP}(\mathrm{mmHg})$ & $52.3 \pm 16.4$ & $52.9 \pm 17.1$ & $67.2 \pm 16.2$ & $59.7 \pm 17.4 \#$ \\
Treatment & & $117.6 \pm 31.5$ & $117.0 \pm 29.8$ & $108.4 \pm 28.4^{*}$ & $104.6 \pm 29.8^{*}$ \\
Control & $\mathrm{Heart} \mathrm{rate}(\mathrm{bpm})$ & $124.5 \pm 34.5$ & $123.7 \pm 32.1$ & $106.2 \pm 24.9^{*}$ & $103.8 \pm 22.9^{*}$ \\
Treatment & & $19.6 \pm 8.2$ & $20.6 \pm 8.4$ & $28.1 \pm 9.7 \#$ & $35.7 \pm 9.9^{*}$ \\
Control & $\mathrm{UV}(\mathrm{ml} / \mathrm{h})$ & $24.6 \pm 9.4$ & $24.7 \pm 8.9$ & $35.1 \pm 8.1 \#$ & $39.2 \pm 9.2^{*}$ \\
\hline
\end{tabular}

Compared with the results before administration, $\# \mathrm{P}<0.05, * \mathrm{P}<0.01$.

\subsection{Follow Up}

The patients were followed up for $30 \mathrm{~d}$. The use time of vasoactive drug, duration of mechanical ventilation and length of stay in ICU were significantly shorter in the treatment group than those in the control group $(\mathrm{P}<0.05)$, but there were no significant differences in the incidence of MODS and mortality between the two groups $(\mathrm{P}>0.05)$ (Table $6)$.

Table 6. Follow-up results.

\begin{tabular}{lllll}
\hline Group & $\begin{array}{l}\text { Discontinued time of } \\
\text { vasoactive drug (h) }\end{array}$ & $\begin{array}{l}\text { Mechanical ventilation duration } \\
\text { (h) }\end{array}$ & $\begin{array}{l}\text { ICU stay length } \\
\text { (d) }\end{array}$ & $\begin{array}{l}\text { MODS } \\
\text { [n(\%)] }\end{array}$ \\
\hline Treatment & $52.6 \pm 14.7 *$ & $163.7 \pm 37.2 *$ & $17.9 \pm 5.8 *$ & $4(19.05 \%)$ \\
Control & $60.1 \pm 13.8$ & $228.4 \pm 47.9$ & $26.9 \pm 6.9$ & $5(23.81 \%)$ \\
\hline
\end{tabular}

$* \mathrm{P}<0.05$ vs the control group.

\section{Discussion}

The pathophysiologic characteristics of severe septic shock are manifested as follows. The decline of systemic vascular resistance accompanied by normal or increased cardiac output is often referred to as high-velocity type hemodynamic status. The basis of hemodynamic change is systolic and diastolic dysfunction of peripheral vessel so as to cause abnormal blood flow distribution, inadequate tissue perfusion, pathological dependence of oxygen supply and consumption, increased capacity of vascular bed, leading to relative capacity insufficiency, and meanwhile capillary permeability increases, intravascular fluid leaks to tissue and the third space, and cardiac function is inhibited. Therefore, about $50 \%$ of severe sepsis patients will appear different forms of left ventricular dysfunction with or without right ventricular hypofunction [9, 10]. B-type natriuretic peptide (BNP), which can be significantly increased during left heart failure, is an independent risk factor for the diagnosis of left heart failure and prognosis evaluation. In recent years, it has been reported that pulmonary arterial hypertension and right ventricular dilatation can also lead to increased plasma BNP. Chung et al. found that plasma BNP level was positively correlated to mean pulmonary artery pressure $(\mathrm{r}=0.73)$, and was related to the severity of right ventricular dysfunction [11].

Lactic acid is produced mainly through anaerobic glycolysis, metabolized and cleared in the liver and kidney, whose elevation reflects the increase of anaerobic metabolism in the case of low perfusion. Early fluid resuscitation aims to maintain venous blood capacity, increase cardiac output and tissue oxygen supply in patients with septic shock, correct hypoperfusion, and the monitoring on lactate dynamic changes, as an indicator that can clearly reflect tissue hypoperfusion LAC quickly and accurately. In this study, the lactate level of the treatment group was significantly lower than that of the control group, and showed a gradual downward trend, which confirms again that early fluid resuscitation under the guidance of PiCCO capacity monitoring can accurately grasp the fluid infusion volume and speed to maintain venous blood capacity and effectively improve tissue and organ perfusion, so as to speed up the discharge of metabolic acidic products, reduce the side effects caused by the accumulation of acidic metabolites as soon as possible, playing an active role in maintaining environmental stability in patients with septic shock, and its direct consequences can lead to the dosage reduction and disuse of 
vasoactive drugs, shorter duration of mechanical ventilation and decreased length of stay in ICU $[12,13]$.

In case of septic shock, due to the abnormal distribution of systemic blood flow, patients may suffer from varying degrees of relative or absolute lack of effective circulating volume. Therefore, fluid resuscitation is one of the important means of circulatory support in patients with septic shock, which can effectively improve tissue perfusion. Studies have shown that the application of colloidal liquid on septic shock patients for fluid resuscitation can significantly improve the levels of ITBVI and ITBVI of patients with different degrees of pulmonary edema and significantly improve the CI and SI levels of patients with relatively high lung water [14, 15]. Although septic shock patients may experience increased EVLWI and CVP to varying degrees in the fluid resuscitation process, especially for those whose lung water level has been already high, the temporary increase of lung water cannot affect oxygenation and respiratory function. EVLWI, as a quantitative indicator for pulmonary edema, can provide the pathological process of its occurrence, development and evolution in an early, sensitive, intuitive way, helping guide its treatment and prognosis [16, 17]. The EVLWI has a significant correlation with duration of mechanical ventilation, length of stay and mortality of patients with severe infection and septic shock. Extravascular lung water monitoring experiences the development process from qualitative to quantitative analysis, from invasion to non-invasion, from experiment to the clinic and then to the bedside. There are many methods for EVLW measurement, such as X-ray chest radiograph, indirect method of measurement, dry weight method, double-tracer dilution method and PiCCO; but EVLWI measured by PiCCO to reflect the severity of pulmonary edema is most convenient and reliable.

Increased capillary permeability in septic shock patients may result in the loss of albumin, tissue edema and pulmonary edema. Although there is no generally-accepted recommendation for the selection of fluid for resuscitation with the best effect, it is found that more total crystalloid solution is needed than colloid solution for fluid resuscitation. In this process, whether crystalloid solution has an impact on oxygenation or not needs to be confirmed by further research $[18,19]$. Therefore, the blood volumes of patients in early resuscitation in this study were markedly increased and maintained more than $12 \mathrm{~h}$. In the early stage of resuscitation, even patients with increased lung water may have no obvious deterioration of oxygenation after resuscitation. In addition, to increase colloid osmotic pressure cannot effectively reduce lung water. Therefore, non-high-capacity fluid resuscitation may be also applied to patients with pulmonary edema. Currently, septic shock is a difficult problem in the work of ICU. Its mortality increases with the severity of the disease which needs to be able to quickly raise blood pressure, improve blood perfusion of the heart and increase the perfusion of vital organs so as to improve tissue ischemia, hypoxia and to prevent the occurrence of multiple organ failure [20].

\section{Conclusion}

In summary, by monitoring the changes of CI, EVLW I, ITBVI and GEDVI, PiCCO monitoring technology can show the volume status of patients with septic shock in a dynamic, accurate and intuitive way. The early fluid resuscitation under the guidance of PiCCO has significant effect, and meanwhile the PiCCO monitoring is simple, minimally invasive and safe, which can substitute for CVP to be one of hemodynamic monitoring indicators for EGDT.

\section{References}

[1] m-positive cocci and senile systemic amyloidosis]. Medicina (B Aires) 2019; 72: 521-526.

[2] Martí-Carvajal AJ, Solà I, Gluud C, Lathyris D, Cardona AF, Human recombinant protein $\mathrm{C}$ for severe sepsis and septic shock in adult and paediatric patients. Cochrane Database Syst Rev 2019; 12: 4388-4391.

[3] Nakashidze I, Tsintsadze N, Potskhishvili Sh. [Protocol of the management of patients with severe sepsis and septic shock]. Georgian Med News 2019; 16: 40-45.

[4] Higuchi T. Series: Knowledge of emergency required for internist; severe sepsis and septic shock. Nihon Naika Gakkai Zasshi 2019; 101: 2982-2987.

[5] Alvarez J, Mar J, Varela-Ledo E, Garea M, Matinez-Lamas L, Rodriguez $\mathrm{J}$, et al. Cost analysis of real-time polymerase chain reaction microbiological diagnosis in patients with septic shock. Anaesth Intensive Care 2019; 40: 958-963.

[6] Jung B, Clavieras N, Nougaret S, Molinari N, Roquilly A, Cisse M, et al. Effects of etomidate on complications related to intubation and on mortality in septic shock patients treated with hydrocortisone: a propensity score analysis. Crit Care 2019; 16: 224-228.

[7] Hvidt LN, Perner A. High dosage of dextran 70 is associated with severe bleeding in patients admitted to the intensive care unit for septic shock. Dan Med J 2019; 59: 4531-4534.

[8] Capuzzo M, Rambaldi M, Pinelli G, Campesato M, Pigna A, Zanello $\mathrm{M}$, et al. Hospital staff education on severe sepsis/septic shock and hospital mortality: an original hypothesis. BMC Anesthesiol 2019; 12: 28-31.

[9] Park DW, Chun BC, Kim JM, Sohn JW, Peck KR, Kim YS, et al. Epidemiological and clinical characteristics of community-acquired severe sepsis and septic shock: a prospective observational study in 12 university hospitals in Korea. J Korean Med Sci 2019; 27: 1308-1314.

[10] Grønlykke L, Brandstrup SL, Perner A. Data from clinical database on septic shock are valid. Dan Med J 2019; 59: $4522-4524$.

[11] Chung KP, Chang HT, Huang YT, Liao CH, Ho CC, Jerng JS, et al. Central Venous Oxygen Saturation Under Non-Protocolized Resuscitation Is Not Related to Survival in Severe Sepsis or Septic Shock. Shock 2019; 38: 584-591.

[12] Surani SR, Ratnani I, Guntupalli B, Bopparaju S. Severe insulin resistance treatment with intravenous chromium in septic shock patient. World J Diabetes 2019; 3: 170-173. 
[13] Graebin P, Veit TD, Alho CS, Dias FS, Chies JA. Polymorphic variants in exon 8 at the 3' UTR of the HLA-G gene are associated with septic shock in critically ill patients. Crit Care 2019; 16: 211-214.

[14] Hsu JL, Liu V, Patterson AJ, Martin GS, Nicolls MR, Russell JA. Potential for overuse of corticosteroids and vasopressin in septic shock. Crit Care 2019; 16: 447-450.

[15] Tamayo E, Fernández A, Almansa R, Carrasco E, Goncalves L, Heredia $M$, et al. Beneficial role of endogenous immunoglobulin subclasses and isotypes in septic shock. $J$ Crit Care 2019; 27: 616-622.

[16] Enrico C, Kanoore Edul VS, Vazquez AR, Pein MC, Pérez de la Hoz RA, Ince C, et al. Systemic and microcirculatory effects of dobutamine in patients with septic shock. J Crit Care 2019; 27: $630-638$.

[17] Lanspa MJ, Brown SM, Hirshberg EL, Jones JP, Grissom CK.
Central venous pressure and shock index predict lack of hemodynamic response to volume expansion in septic shock: A prospective, observational study. J Crit Care 2019; 27: 609-615.

[18] Yussof SJ, Zakaria MI, Mohamed FL, Bujang MA, Lakshmanan S, Asaari AH. Value of Shock Index in prognosticating the short-term outcome of death for patients presenting with severe sepsis and septic shock in the emergency department. Med J Malaysia 2019; 67: 406-411.

[19] Hisamuddin NA, Azlan K. The use of laboratory and physiological parameters in predicting mortality in sepsis induced hypotension and septic shock patients attending the emergency department. Med J Malaysia 2019; 67: 259-264.

[20] Gaines NN, Patel B, Williams EA, Cruz AT. Etiologies of septic shock in a pediatric emergency department population. Pediatr Infect Dis J 2019; 31: 1203-1205. 